\title{
Methanol dynamics in H-ZSM-5 with Si/Al ratio of 25: a quasi-elastic neutron scattering (QENS) study
}

\author{
Santhosh K. Matam ${ }^{1,2}$ (]) C. Richard A. Catlow ${ }^{1,2,3} \cdot \operatorname{lan}$ P. Silverwood ${ }^{1,4} \cdot$ Alexander J. O'Malley $^{1,5}$ (])
}

Accepted: 10 May 2021 / Published online: 29 June 2021

(c) Crown 2021

\begin{abstract}
Methanol dynamics in zeolite H-ZSM-5 (Si/Al of 25) with a methanol loading of $\sim 30$ molecules per unit cell has been studied at 298, 323, 348 and $373 \mathrm{~K}$ by incoherent quasi-elastic neutron scattering (QENS). The elastic incoherent structure factor (EISF) reveals that the majority of methanol is immobile, in the range between 70 and $80 \%$, depending on the measurement temperature. At $298 \mathrm{~K}, \approx 20 \%$ methanol is mobile on the instrumental timescale, exhibiting isotropic rotational dynamics with a rotational diffusion coefficient $\left(D_{\mathrm{R}}\right)$ of $4.75 \times 10^{10} \mathrm{~s}^{-1}$. Upon increasing the measurement temperature from 298 to $323 \mathrm{~K}$, the nature of the methanol dynamics changes from rotational to translational diffusion dynamics. Similar translational diffusion rates are measured at 348 and $373 \mathrm{~K}$, though with a larger mobile fraction as temperature increases. The translational diffusion is characterised as jump diffusion confined to a sphere with a radius close to that of a ZSM-5 channel. The diffusion coefficients may be calculated using either the Volino-Dianoux (VD) model of diffusion confined to a sphere, or the Chudley-Elliot (CE) jump diffusion model. The VD model gives rise to a self-diffusion co-efficient $\left(D_{\mathrm{s}}\right)$ of methanol in the range of 7.8-8.4 $\times 10^{-10} \mathrm{~m}^{2} \mathrm{~s}^{-1}$. The CE model gives a $D_{\mathrm{s}}$ of around $1.2( \pm 0.1) \times 10^{-9} \mathrm{~m}^{2} \mathrm{~s}^{-1}$ with a jump distance of 2.8 (either +0.15 or -0.1$) \AA$ and a residence time $(\tau)$ of $\sim 10.8$ (either +0.1 or -0.2 ) ps. A correlation between the present and earlier studies that report methanol dynamics in H-ZSM-5 with Si/Al of 36 is made, suggesting that with increasing Si/Al ratio, the mobile fraction of methanol increases while $D_{\mathrm{R}}$ decreases.
\end{abstract}

Keywords Zeolite $\cdot$ H-ZSM-5 $\cdot$ Methanol $\cdot$ QENS $\cdot$ Diffusion $\cdot$ Rotational $\cdot$ Translational

Santhosh K. Matam

santhosh.matam@rc-harwell.ac.uk

http://www.ukcatalysishub.co.uk

$\triangle$ Alexander J. O’Malley

a.o'malley@bath.ac.uk

1 UK Catalysis Hub, Research Complex at Harwell, Science and Technology Facilities Council, Rutherford Appleton Laboratory, Didcot OX11 0FA, UK

2 Cardiff Catalysis Institute, School of Chemistry, Cardiff University, Cardiff CF10 3AT, UK

3 Department of Chemistry, University College London, 20 Gordon St., London WC1E 6BT, UK

4 ISIS Pulsed Neutron and Muon Facility, Science and Technology Facilities Council, Rutherford Appleton Laboratory, Didcot OX11 0QX, UK

5 Centre of Sustainable and Circular Technologies, Department of Chemistry, University of Bath, Bath BA2 7AY, UK

\section{Introduction}

Zeolite ZSM-5 plays a crucial role in many commercial petrochemical and environmental processes due to its unique porous architecture and chemical/catalytic properties [1]. Some prominent examples of these processes include methanol to hydrocarbons, hydrocracking and alkylation [1-6]. In microporous catalytic processes, transportation of reactants and/or products to and from the active Brønsted acid site, located within the zeolite pores with distinct pore architecture, involves adsorption, diffusion and then reaction of molecules at the active site. Therefore, in the case of the widely studied methanol to hydrocarbon (MTH) catalysis, diffusion of methanol and products is one of the key factors for an efficient catalytic process [7]. The knowledge of adsorption geometry, diffusion characteristics and reactivity of diffusing molecules within the zeolite pores will help to design and tailor the porous architecture that favours the processes [7-9]. 
The diffusion properties of molecules within catalyst pores are measured by different techniques which are broadly classified into (i) macroscopic and (ii) microscopic [10, 11]. Traditionally employed macroscopic techniques include steadystate permeation, sorption-uptake, chromatography and zero length column methods which are often limited by external heat and mass transfer and response time. Microscopic techniques, however, are capable of measuring diffusivity over much shorter time and length scales than is possible with macroscopic techniques. They include pulsed field gradient nuclear magnetic resonance (PFG-NMR) and quasi-elastic neutron scattering (QENS). QENS enables measurement of dynamical processes over a lengthscale of $0.1-100 \mathrm{~nm}$ and time scales of $10 \mathrm{fs}-100 \mathrm{~ns}[11,12]$. Whereas, PFG-NMR probes with a length scale of $0.1-1 \mu \mathrm{m}$ and time scales in the order of $1 \mathrm{~ms}$ resolution [11]. Moreover, QENS data can be simulated by molecular dynamics (MD) which sample similar time and length scales [11-13]. Applications of QENS in the field of heterogenous catalysis are limited and only a few QENS studies on methanol diffusion in ZSM-5 (with a comparable $\mathrm{Si} / \mathrm{Al}$ ratio of 30 ) have been reported. It is notable that differing conclusions can be found depending on resolution/ energy window of the instrument and methanol loading used even in zeolites with comparable Si/Al ratios. [14-17]. For example, one study concluded that methanol diffuses along the ZSM-5 channels with a diffusion coefficient in the order of $10^{-11} \mathrm{~m}^{2} \mathrm{~s}^{-1}$ using the high resolution IN10 instrument at ILL, Grenoble [14], while other studies employing lower resolution spectrometers (with wider energy windows) were not able to observe long range methanol diffusion [15-17]. We note that these measurements were conducted on different instruments with varied instrument resolutions [14-17].

The objective of the present work is to utilise QENS (measured employing the instrumentation at ISIS Neutron and Muon Source at Harwell, UK) to study methanol diffusion dynamics in zeolite $\mathrm{H}-\mathrm{ZSM}-5(\mathrm{Si} / \mathrm{Al}=25)$ as a function of temperature. A comparison with previously reported studies enabled us to assess the effect of $\mathrm{Si} / \mathrm{Al}$ ratio on methanol diffusion dynamics in ZSM-5. The results show that the methanol mobility is more restricted in the zeolite studied here than that reported previously with a higher $\mathrm{Si} / \mathrm{Al}$ ratio $(\mathrm{Si} / \mathrm{Al} \geq 30)$, especially at room temperature, in line with the higher acid site density of this zeolite.

\section{Experimental}

\subsection{Zeolite H-ZSM-5}

The $\mathrm{NH}_{4}-\mathrm{ZSM}-5$ zeolite $(\mathrm{Si} / \mathrm{Al}=25)$ was procured from Zeolyst International, Inc. The zeolite was calcined in air at $500{ }^{\circ} \mathrm{C}$ for $24 \mathrm{~h}$ to remove residual template and to obtain H-ZSM-5. Prior to the quasi-elastic neutron scattering
(QENS) experiments, the zeolite was dehydrated under vacuum $\left(10^{-3}\right.$ to $\left.10^{-4} \mathrm{mbar}\right)$ at $350^{\circ} \mathrm{C}$ for $12 \mathrm{~h}$ and thereafter handled in an argon-filled glovebox. For the methanol loaded samples, methanol (Sigma-Aldrich, $\geq 99.9 \%$ ) loading was conducted at room temperature by flowing dry $\mathrm{N}_{2}$ $\left(100 \mathrm{~mL} \mathrm{~min}^{-1}\right)$ through a methanol saturator that consisted of a Dreschel bottle at the same temperature [18]. The loading was continued until there was no further uptake by the zeolite (gravimetrically determined) and resulted in a methanol loading of around 30 molecules per unit cell (i.e., $\approx 7.5$ molecules per acidic site) [18]. The thin walled aluminium containers of annular geometry were loaded with zeolite under an argon atmosphere in the glovebox.

\subsection{Quasi-elastic neutron scattering (QENS)}

The zeolite H-ZSM-5 with and without methanol loading were analysed by QENS using the time-of-flight backscattering OSIRIS spectrometer at the ISIS Facility (STFC Rutherford Appleton Laboratory, Chilton, UK) [16,17 and references therein]. The sample container was placed in a top loading closed cycle refrigerator and a resolution measurement of each undosed (i.e., without methanol) zeolite sample was obtained at a base temperature of around $10 \mathrm{~K}$. QENS measurements were then subsequently conducted at $298,323,348$ and $373 \mathrm{~K}$ on both zeolites with and without the methanol load. The QENS data collected without methanol loading were subtracted from the data obtained with the loaded zeolite. The zeolite with the methanol load measured at base temperature was used as the instrumental resolution function for data fitting. Pyrolytic graphite 002 analyser crystals were used which resulted in an energy resolution of $24.5 \mu \mathrm{eV}$ with energy transfers measured in a window of $\pm 0.55 \mathrm{meV}$ and with a $\mathrm{Q}$ range of $0.2-1.75 \AA^{-1}$. The data reduction was performed using the MantidPlot software [19]. The data fitting was conducted by the neutron scattering analysis software DAVE (version 2.2) [20].

\section{Results and discussion}

\subsection{Methanol diffusion dynamics at $298 \mathrm{~K}$}

The experimental QENS data collected at all studied temperatures were fitted to the combination of a delta function, a single Lorentzian function that accounts for the quasi-elastic broadening of the scattering function and a linear background function convoluted with the resolution data measured at $10 \mathrm{~K}$. Selected QENS data at $298 \mathrm{~K}$ are plotted as a function of momentum transfer (Q) in Fig. 1a, along with the Lorentzian function and the total fit. There is a significant elastic component 
(intensity within the width of the instrumental resolution) which is particularly high at low $\mathrm{Q}$ values. This intensity decreases with increasing $\mathrm{Q}$, and the intensity of the quasielastic component fit by the Lorentzian function increases (becoming particularly significant above $0.9 \AA^{-1}$ ) which is typically observed for methanol loaded H-ZSM-5 [17]. In general, methanol mobility over a longer length scale, i.e. translational diffusion, can be expected at lower Q $\left(<1 \AA^{-1}\right)$, while higher energy localised methanol dynamics such as rotational motions can be anticipated at higher $\mathrm{Q}$ values $\left(>1 \AA^{-1}\right)[11-13]$. The significant decrease in elastic intensity at higher $\mathrm{Q}$ indicates the observation of localised methanol dynamics [17, 21]. A large elastic peak intensity at lower $\mathrm{Q}$ between 0.24 and $0.9 \AA^{-1}$ reflects the absence of longer range translational dynamics of methanol (within the instrumental time resolution of $\approx 1-100 \mathrm{ps})[17,21]$. Indeed, at lower $\mathrm{Q}$, the resolution function mainly describes the data, suggesting that the quasi-elastic component, characterised by the Lorentzian function is not significant (see Fig. S1, Supplementary Information (SI)). This observation is in line with previous work that reported no quasi-elastic broadening of the signal of methanol loaded H-ZSM-5 at room temperature (certainly at low Q), though the methanol loading and $\mathrm{Si}$ / Al ratio of H-ZSM-5 differ slightly among the reports [14-17, 21].

The significant elastic intensity is attributed to the immobile methanol due either to hydrogen bonding [14-16] or methoxylation [16]. Indeed, complementary diffuse reflectance infrared Fourier transformed spectroscopy (DRIFTS) studies show that both hydrogen bonded methanol and methoxy species are present under these experimental conditions

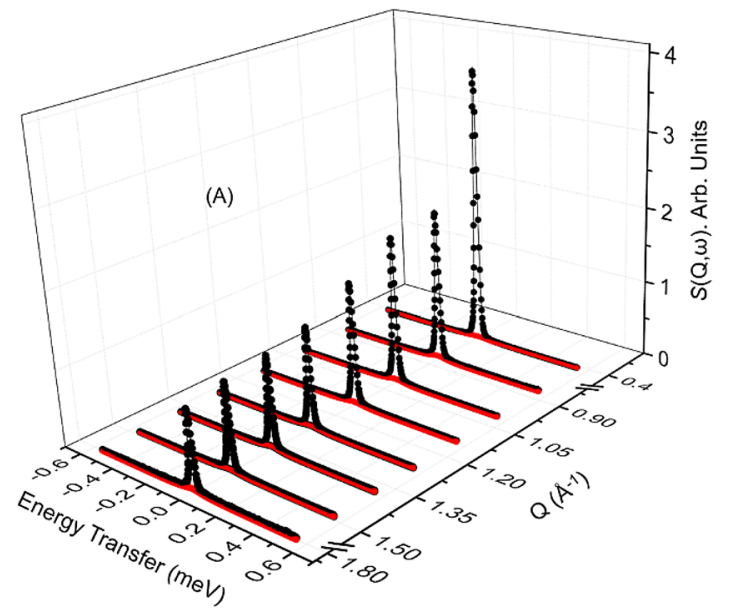

Fig. 1 A QENS spectra of methanol loaded H-ZSM-5 at $298 \mathrm{~K}$. Experimental data (filled circles), total fit (solid black line) and the Lorentzian function (red). Selected spectra are shown for clarity. B The corresponding experimental elastic incoherent structure factor (EISF) data (green diamond symbols) of methanol in $\mathrm{H}-\mathrm{ZSM}-5$
$[18,22]$. Besides immobile methanol, the presence of a fraction of locally mobile methanol is also reported previously $[14,17,21]$ by analysing the elastic incoherent structure factor (EISF), which is the ratio between the elastic peak intensity and total peak intensity [11-14, 17, 21]. Such localised methanol dynamics can be characterised by different theoretical models that are discussed in detail in references [11-14, 17, 21]. Briefly, the models include whole molecule isotropic rotation [23], translational diffusion confined within a sphere (Volino-Dianoux model) [24] and 3-site jump rotation of the methyl groups $[17,21]$. Based on these models, the experimental EISF is analysed. It is important to note that the use of the 3-site jump rotation model can only be applied with a maximum $75 \%$ of the protons treated as mobile, as we assume the hydroxyl proton would be anchored to a Brønsted acidic site. The experimental EISF is plotted in Fig. 1B and decreases with increasing Q. The absolute intensity decay as a function of $\mathrm{Q}$ is around $20 \%$, which is around $50 \%$ lower than those reported previously $[17,21]$. It suggests that the localised methanol dynamics are even more restricted in a H-ZSM-5 sample with $\mathrm{Si} /$ $\mathrm{Al}=25$ than in previously reported samples with lower aluminium content $(\mathrm{Si} / \mathrm{Al}>30)$. Indeed, simple models with a mobile fraction of 0.75 assigned to 3 -site model, as noted earlier, could not fit the experimental EISF, due to the fact that the methanol loaded H-ZSM-5 may show significant interactions with acid sites at room temperature as evident from QENS and also from inelastic neutron scattering (INS) and DRIFTS [16, 18, 22]. Therefore, the effective EISF is considered to include a fraction of immobile methanol in the models as detailed in previous studies [17, 21]. Models, with the static fraction included are now compared with

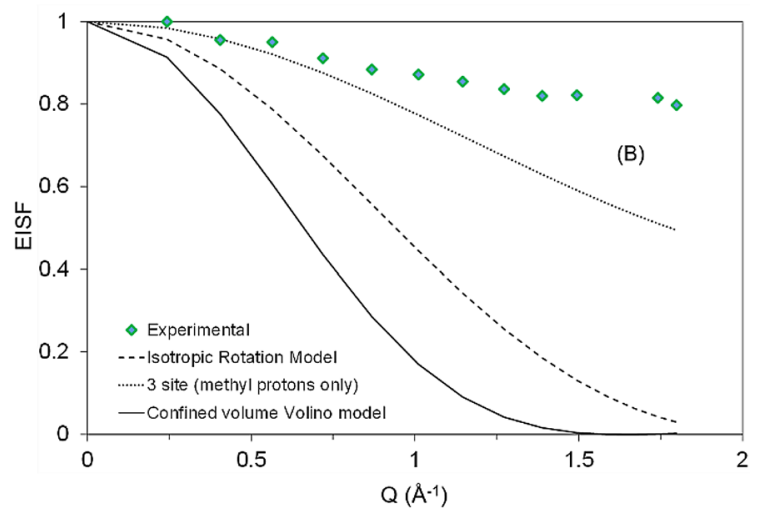

at $298 \mathrm{~K}$ are compared with different theoretical models that are discussed in detail in [11-14, 17, 21]. The experimental EISF values at $\mathrm{Q}$ between 1.58 and 1.67 are not included in B panel due to contributions from Bragg peaks 
the experimental EISF in Fig. 2A. For the 3-site model, we again assume a mobile fraction of 0.75 .

It can be readily seen that the experimental EISF now adequately fits to the isotropic methanol rotation model with a mobile fraction of $21 \%$, which is $50 \%$ lower than that reported in H-ZSM-5 with Si/Al of 30 (with mesopores present due to dealumination) and $36[17,21]$. The 3 -site 'methyl' jump rotation model fails to fit the data, even when only a fraction of methyl protons is considered as mobile, while translational diffusion of methanol in a confined spherical volume (with a radius of $2.75 \AA$ ) model shows a potential agreement with the experimental EISF. However, analysis of quasi-elastic broadening of the spectra by plotting the full width at half maxima (FWHM) of the Lorentzian function with $\mathrm{Q}^{2}$ as in Fig. $2 \mathrm{~B}$ suggests we are more likely observing isotropic methanol rotation, the model of which is also shown to fit the experimental EISF. The FWHM appear to be $\mathrm{Q}^{2}$ independent, which is characteristic of localised dynamics where the $\mathrm{Q}$ resolution is insufficient to distinguish motion in real space, such as isotropic rotation, but not of longer range translational diffusion whether it be Fickian in nature, jump diffusion or confined to a spherical volume $[17,21]$. The FWHM give rise to an isotropic methanol rotational diffusion coefficient $\left(D_{\mathrm{R}}\right)$ of $4.75 \times 10^{10} \mathrm{~s}^{-1}$ similar to that reported in [21], which is of the same order of magnitude as reported previously [17].

\subsection{Methanol diffusion dynamics at higher temperatures}

QENS spectra collected at $323 \mathrm{~K}$ are plotted together with the Lorentzian function and the total fit as a function of $\mathrm{Q}$ in Fig. 3A (for more clarity see Fig. S2 in SI). The elastic intensity decreases with increasing Q, as observed at $298 \mathrm{~K}$

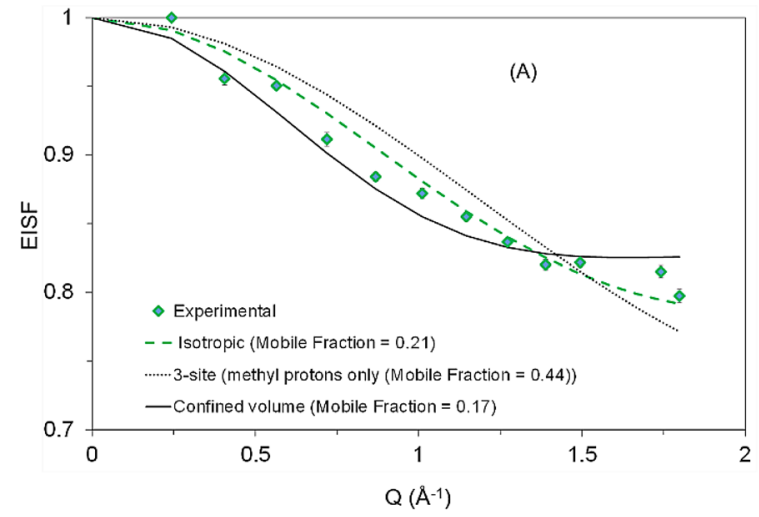

Fig. 2 A Experimental EISF data of methanol in H-ZSM-5 at $298 \mathrm{~K}$, modelled by including a fraction of immobile methanol in different theoretical models. The mobile methanol fraction is shown in parenthesis and the radius of the confined spherical radius of $2.75 \AA$ is considered. The EISF values at Q between 1.58 and 1.67 are not con-
(Fig. 1A). As expected, the individual theoretical models alone could not fit the experimental EISF. Therefore, the effective EISF which includes an immobile methanol fraction in the models is considered and compared in Fig. 3B. The isotropic methanol rotation and the 3-site methyl jump rotation models fail to fit the experimental EISF, while the model of translational diffusion confined to a sphere fits the data very well with a spherical radius of $2.75 \AA$, and a mobile methanol fraction of $22 \%$ (Table 1).

It is noteworthy that the methanol dynamics have changed from rotational to translational diffusion on increasing the measurement temperature from 298 to $323 \mathrm{~K}$, which is in line with the previously observed temperature dependent methanol dynamics [17, 21]. Interestingly, the mobile fraction of $22 \%$ is similar to that observed at $298 \mathrm{~K}$, although the fraction is derived from two different models (confined diffusion $v s$ rotational model) suggesting that very little extra methanol has become mobile with this temperature increase, but the amount that is mobile, has switched from rotational to translational motions as observed previously [21]. The same Volino-Dianoux (VD) [24] confined diffusion model indicates that the mobile fraction increases with increasing measurement temperature from $323 \mathrm{~K}$ to 348 and to $373 \mathrm{~K}$, as expected (Table 1) and the model fits the data very well (Figs. S3 and S4, see Supplementary Information). Upon analysing the half width half maxima (HWHM) of the Lorentzian function as a function of $\mathrm{Q}^{2}$ (Fig. 3C), it is found that the broadenings fit to the Chudley-Elliot (CE) jump diffusion model (the fitting parameters of which will be discussed shortly) [25]. However, it is also observed that the HWHM deviates from this model and plateaus below $\mathrm{Q}^{2}=1.3 \AA^{-2}$. This observation is consistent with jump diffusion confined to a sphere, as has been

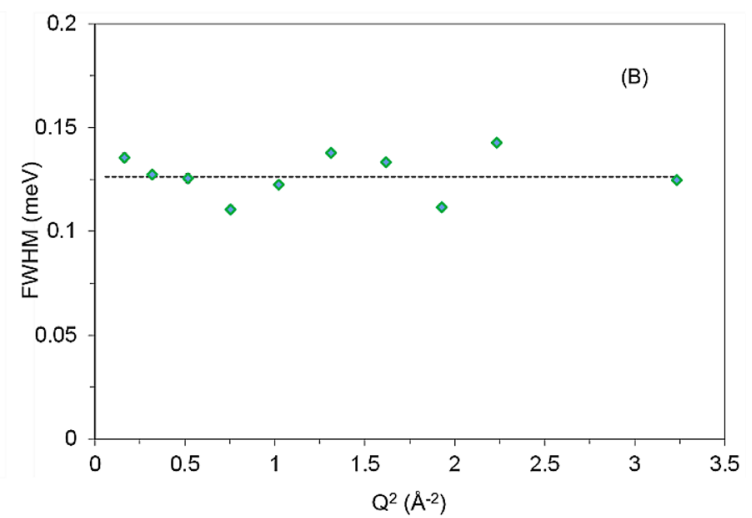

sidered due to contribution from Bragg peaks. B The FWHM of the Lorentzian function is plotted as a function of $\mathrm{Q}^{2}$. The FWHM values at 2.52, 2.79 and $3.03 \AA^{-2}$ are discounted due to contribution from Bragg peaks 
Fig. 3 A QENS spectra of methanol in H-ZSM-5 at 323 K. Experimental data (filled circles), total fit (solid black line) and the Lorentzian function (red). Selected spectra are shown for clarity. B Experimental EISF data of methanol in H-ZSM-5 at $323 \mathrm{~K}$, modelled by including a fraction of immobile methanol in different theoretical models. The mobile methanol fraction is shown in the parenthesis of panel (B) and a confined volume radius of $2.75 \AA$ is used. C The $\mathrm{Q}$ independent at lower $\mathrm{Q}\left(<1.25 \mathrm{Q}^{2}\right)$ represents the HWHM of the Lorentzian function that fits reasonably well to the Volino-Dianoux confined diffusion model. The Q dependence of the Lorentzian function HWHM at higher $\mathrm{Q}>1 \mathrm{Q}^{2}$ ) fits well to the Chudley-Elliot jump diffusion model. The $\mathrm{Q}^{2}$ value corresponding to the $2.75 \AA$ radius of the confined sphere of the Volino-Dianoux model is indicated by the dashed black vertical line. EISF (B) and HWHM (C) values at Q of 1.58 and 1.67 are not considered due to contribution from Bragg peaks
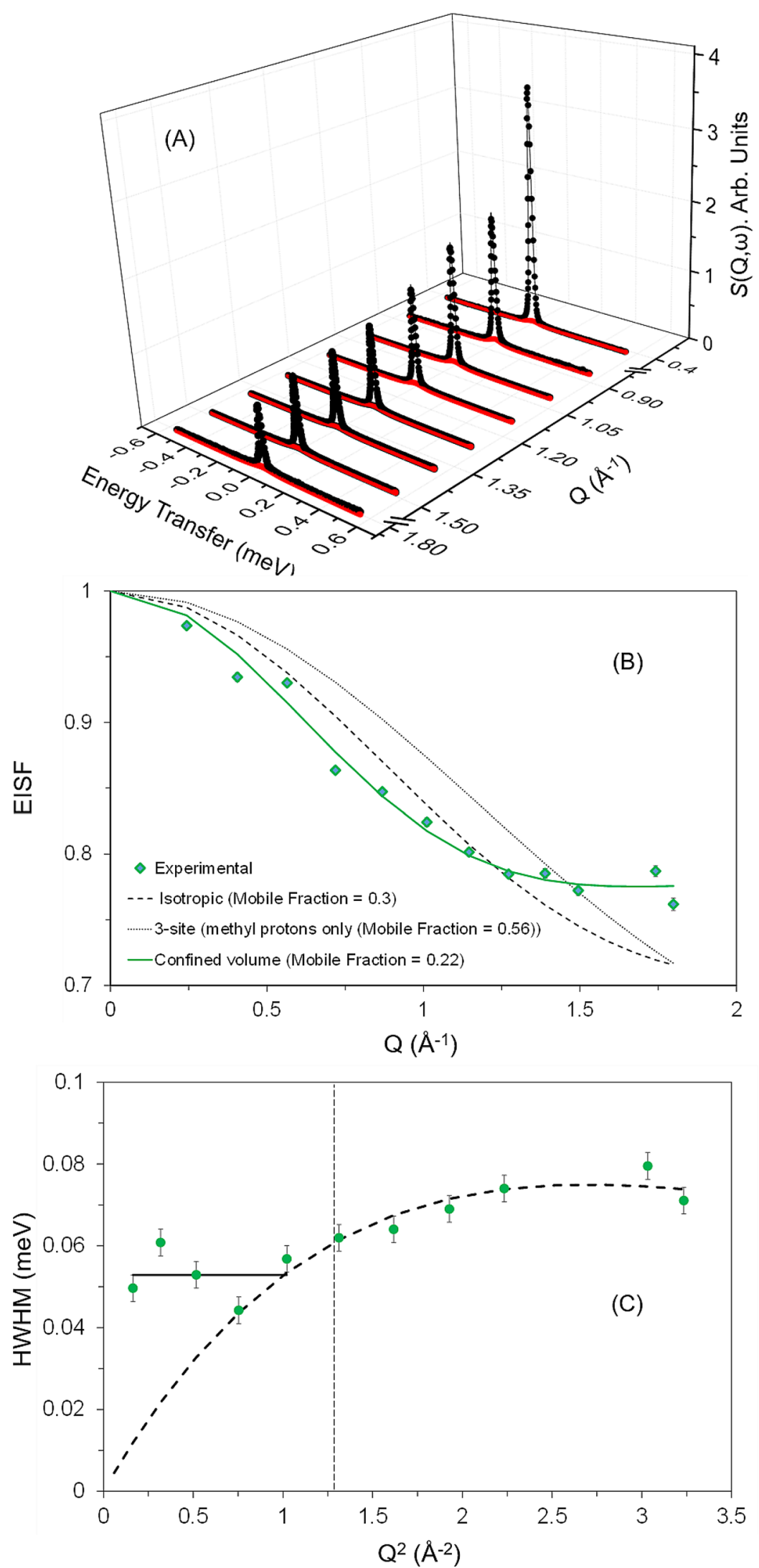
Table 1 Diffusion coefficients and mobile fractions derived from fitting QENS data with different models, for methanol in H-ZSM-5 with a Si/Al ratio of 25

\begin{tabular}{lllll}
\hline$T(\mathrm{~K})$ & $\begin{array}{l}\text { Mobile frac- } \\
\text { tion }(\%)\end{array}$ & $\begin{array}{l}\text { Self-diffusion co-efficient }(D \mathrm{~s}), \\
\mathrm{m}^{2} / \mathrm{s}\end{array}$ & $\begin{array}{l}\text { Residence } \\
\text { time }(\tau), \\
\mathrm{ps}^{\mathrm{c}}\end{array}$ \\
\cline { 3 - 4 } & & $\begin{array}{l}\text { Volino- } \\
\text { Dianoux } \\
\text { model }^{\mathrm{b}}\end{array}$ & $\begin{array}{l}\text { Chudley- } \\
\text { Elliot model }^{\mathrm{c}}\end{array}$ & \\
\hline 298 & $21^{\mathrm{a}}$ & - & - & - \\
323 & $22^{\mathrm{b}}$ & $9.2 \times 10^{-10}$ & $1.15 \times 10^{-9}$ & 10.8 \\
348 & $28^{\mathrm{b}}$ & $8.2 \times 10^{-10}$ & $1.2 \times 10^{-9}$ & 10.9 \\
373 & $32^{\mathrm{b}}$ & $9.2 \times 10^{-10}$ & $1.3 \times 10^{-9}$ & 10.6 \\
\hline
\end{tabular}

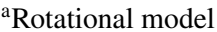

${ }^{\mathrm{b}}$ Confined diffusion Volino-Dianoux model

${ }^{\mathrm{c}}$ Chudley-Elliot jump diffusion model with a jump distance of 2.8 (either +0.15 or -0.1$) \AA$ depending on temperature

previously observed in studies of both methanol in ZSM-5 at higher $\mathrm{Si} / \mathrm{Al}$ ratios [21] and ammonia in smaller pore LEV zeolites [26]. According to the VD model of diffusion confined to a sphere, the plateau occurs at a $Q$ value corresponding to the diameter of the sphere of confinement and the energy value at this plateau point and below corresponds to the self-diffusion coefficient $\left(D_{\mathrm{s}}\right)$ [24]. In the present study the plateau point at $\mathrm{Q}^{2}=1.3 \AA^{-2}$ is consistent with a confining sphere with a radius of around $2.75 \AA$, which matches the pore diameter of $5.5 \AA$ in zeolite H-ZSM-5. The model indicates the $\mathrm{Q}^{2}$ value of plateauing at and below $1.3 \AA^{-2}$, which is indicated by a dashed black line in Fig. 3C. The $D_{\mathrm{s}}$ from the fitting of the low $\mathrm{Q}$ broadenings using the VD model is calculated to be $9.2 \times 10^{-10} \mathrm{~m}^{2} \mathrm{~s}^{-1}$ (Table 1), of a similar magnitude with previous work [21]. The $D_{\mathrm{s}}$ values derived for the data collected at 323,348 and $373 \mathrm{~K}$ are too close (Table 1) to extract a reliable activation energy $\left(\mathrm{E}_{\mathrm{a}}\right)$ for the confined methanol diffusion, unlike the analysis reported in [21].

As mentioned, the HWHM above $\mathrm{Q}^{2}=1\left(\AA^{-2}\right)$ (Fig. 3C) may be fit to the $\mathrm{CE}$ model of jump diffusion, again, consistent with jump diffusion confined to a spherical volume. The fitting of this jump model with a jump distance of around $2.7 \AA$ with a residence time of $\sim 11$ ps at all temperatures (Table 1). One may also calculate the self-diffusion coefficient using the jump parameters stated here using the relation outlined in $[11,14]$. The predicted residence time $(\tau)$ and self-diffusion co-efficient $(D s)$ are tabulated in Table 1 and are very similar at all temperatures. However, we note that the mobile fraction increases from 22 to $32 \%$ from 323 to $373 \mathrm{~K}$. We also note that the jump distance and residence time are slightly longer and lower, respectively, than that reported for zeolite H-ZSM-5 with Si/Al of 36 at comparable temperatures [21].
Based on the comparison with previous studies on H-ZSM-5 with Si/Al of 30 [17] and 36 [21], a correlation between the methanol mobile fraction $(\%)$ and rotational diffusion coefficient $\left(D_{R}\right)$ as a function of $\mathrm{Si} / \mathrm{Al}$ ratio is plotted in Fig. 4. It is evident that the mobile fraction increases and isotropic methanol rotational diffusion coefficient $\left(D_{\mathrm{R}}\right)$ decreases with increasing $\mathrm{Si} / \mathrm{Al}$ ratio of H-ZSM-5 from 25 [present study] to 30 [17] and to 36 [21] (Fig. 4), which is attributed to the acid site density of the zeolites; the higher the acid site density the lower the mobile fraction. However, the comparison between zeolites with $\mathrm{Si} / \mathrm{Al}$ ratio of 25 and 36 with that of 30 should be treated with caution due to the formation of a fraction of larger pores due to dealumination of H-ZSM-5 during the MTH process and measurement temperature. Nonetheless, the comparison presents a clear composition dependent methanol rotational dynamics in zeolite H-ZSM-5. In line with this, further increase in $\mathrm{Si}$ / $\mathrm{Al}$ of the zeolite from 36 to 135 is shown in previous work to have led to a switch from $D_{\mathrm{R}}$ to translational diffusion dynamics of methanol ( $D \mathrm{~s}$ ) (at a similar methanol loading and measurement temperature) [21].

Interestingly, the $D$ s obtained within a confined spherical volume appears to be similar in magnitude in zeolites with $\mathrm{Si} / \mathrm{Al}$ ratio of 25 (Table 1), 36 and 135 [21]; for example, $D \mathrm{~s}$ of $8.8-9.2 \times 10^{-10} \mathrm{~m}^{2} \mathrm{~s}^{-1}$ observed at $373 \mathrm{~K}$. Computational studies are in progress to assess the relationship between $\mathrm{Si} /$ Al ratio of H-ZSM-5 and the longer range translational diffusion of methanol.

\section{Summary and conclusions}

Methanol diffusion dynamics in zeolite H-ZSM-5 (Si/Al of 25 ) with a methanol loading of $\sim 30$ molecules per unit cell have been studied by incoherent quasi elastic neutron scattering (QENS) at 298, 323, 348 and $373 \mathrm{~K}$. The experimental QENS data fit to a delta function convoluted with the resolution data collected at $10 \mathrm{~K}$, a Lorentzian function that accounts for the quasi-elastic broadening and a background function. Based on the fitting, the following main conclusions can be drawn:

(i) Methanol diffusion dynamics are, as expected, temperature dependent: the higher the temperature, the greater the methanol mobility. However, the majority of the methanol in H-ZSM-5 remains immobile, in the range of 70-80\%, depending on the measurement temperature, as shown from the effective elastic incoherent structure factor (EISF). At $298 \mathrm{~K}$, around 20\% methanol is mobile and shows isotropic rotational dynamics with a rotational diffusion coefficient $\left(D_{\mathrm{R}}\right)$ of $4.75 \times 10^{10} \mathrm{~s}^{-1}$. The $D_{\mathrm{R}}$ decreases while the mobile fraction of methanol increases with increasing $\mathrm{Si} / \mathrm{Al}$ 
Fig. 4 Correlation between methanol mobile fraction (\%) (open symbols) and rotational diffusion coefficient $\left(\mathrm{D}_{\mathrm{R}}\right)$ (filled symbols) as a function of $\mathrm{Si} / \mathrm{Al}$ ratio of the zeolite $\mathrm{H}-\mathrm{ZSM}-5$. The correlation is derived from the present and previous studies reported in $[17,21]$. The methanol loading varies between 22 and 30 molecules per unit cell (which is at a saturation level) and QENS measurements were conducted between 293 [21], 298 [present study] and 325 [17] K

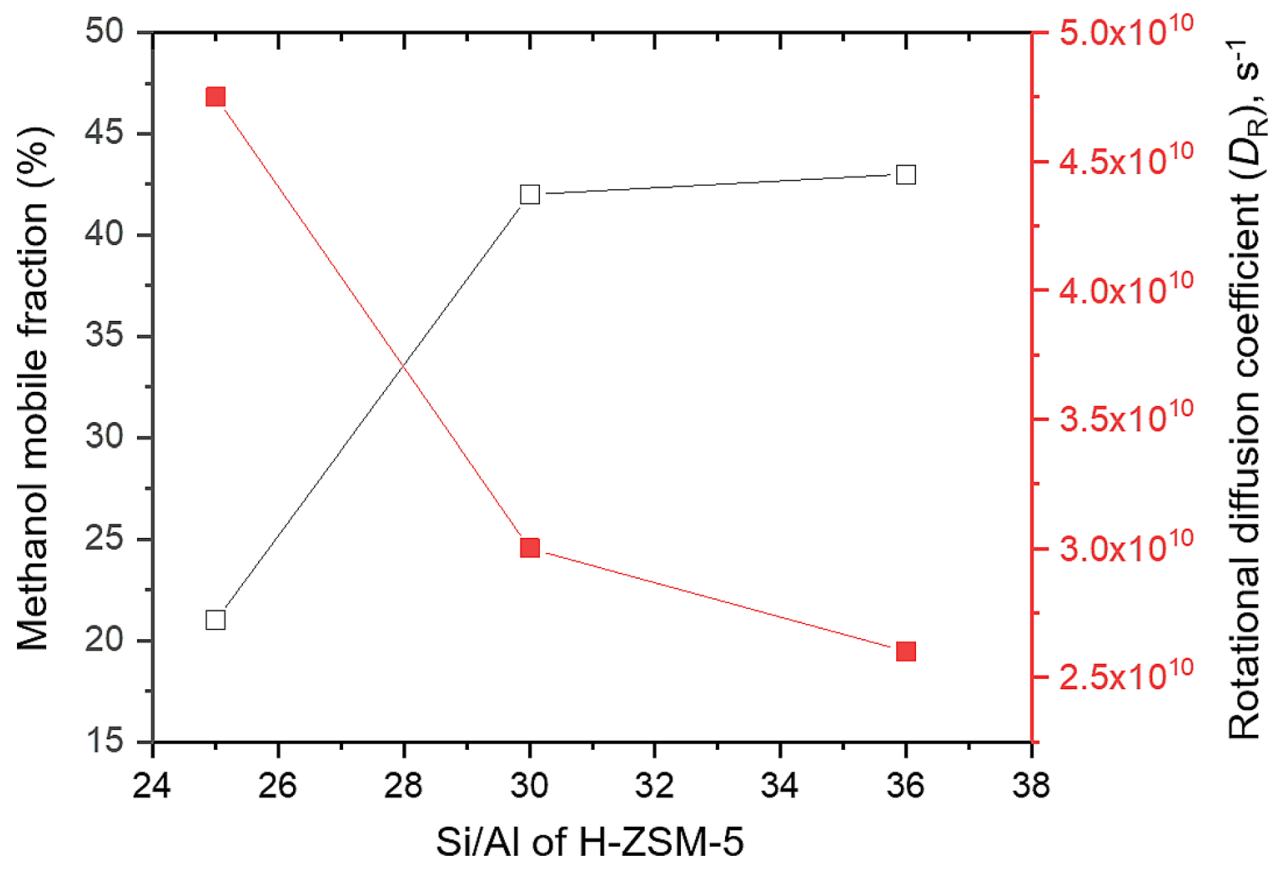

ratio of H-ZSM-5 from 25 to 36 as evident from a correlation between the present and earlier studies.

(ii) The nature of methanol dynamics switches from rotational to translational diffusion on increasing the measurement temperature from 298 to $323 \mathrm{~K}$. Translational diffusion dynamics is observed at similar rates, but with higher mobile populations at 348 and $373 \mathrm{~K}$. Even at $373 \mathrm{~K}$ however, the majority of methanol is still immobile $(\approx 70 \%)$ on the instrumental timescale.

(iii) The translational motion is characterised as jump diffusion confined to a sphere with a radius of $\approx 2.75 \AA$, which matches with the ZSM-5 channel size of $5.5 \AA$. The self-diffusion co-efficient $\left(D_{\mathrm{s}}\right)$ may be quantified using either the VD model of diffusion confined to a sphere or the CE jump diffusion model. Using the VD confined diffusion model to fit the plateaued broadenings at low $\mathrm{Q}, \mathrm{a}_{\mathrm{s}}$ of 8.7 $( \pm 0.5) \times 10^{-10} \mathrm{~m}^{2} \mathrm{~s}^{-1}$ is obtained. The CE jump diffusion model gives a $D_{\mathrm{s}}$ of around $1.2( \pm 0.1) \times 10^{-9}$ $\mathrm{m}^{2} \mathrm{~s}^{-1}$ after fitting a jump distance of around 2.8 (either +0.15 or -0.1$) \AA$ depending on temperature and a residence time $(\tau)$ of around 10.8 (either +0.1 or -0.2) ps at temperatures between 323 and $373 \mathrm{~K}$.

Supplementary Information The online version contains supplementary material available at https://doi.org/10.1007/s11244-021-01450-z.

Acknowledgements The UK Catalysis Hub is kindly thanked for resources and support provided via our membership of the UK Catalysis Hub Consortium and funded by EPSRC Grant: EP/R026939/1,
EP/R026815/1, EP/R026645/1, EP/R027129/1. AJOM acknowledges Roger and Sue Whorrod for the funding of the Whorrod Fellowship. The authors acknowledge the ISIS Neutron and Muon Source at the STFC Rutherford Appleton Laboratory for granting access to OSIRIS instrument and the beamline facilities. The raw experimental data resulted from our beamtime RB1920441 can be found at https://doi. org/10.5286/ISIS.E.RB1920441.

\section{Declarations}

Conflict of interest There are no conflict of interest.

Open Access This article is licensed under a Creative Commons Attribution 4.0 International License, which permits use, sharing, adaptation, distribution and reproduction in any medium or format, as long as you give appropriate credit to the original author(s) and the source, provide a link to the Creative Commons licence, and indicate if changes were made. The images or other third party material in this article are included in the article's Creative Commons licence, unless indicated otherwise in a credit line to the material. If material is not included in the article's Creative Commons licence and your intended use is not permitted by statutory regulation or exceeds the permitted use, you will need to obtain permission directly from the copyright holder. To view a copy of this licence, visit http://creativecommons.org/licenses/by/4.0/.

\section{References}

1. van Speybroeck V, Hemelsoet K, Joos L, Waroquier M, Bell RG, Catlow CRA (2015) Chem Soc Rev 44:7044

2. Chang CD, Silvestri AJ (1977) J Catal 47:249

3. Hunter R, Hutchings GJ (1987) Chem Commun 5:377

4. Svelle S, Visur M, Olsbye U, Saepurahman BM (2011) Topics Catal 54:897

5. Van der Mynsbrugge J, Moors SLC, De Wispelaere K, Van Speybroeck V (2014) ChemCatChem 6:1906 
6. Minova IB, Matam SK, Greenaway A, Catlow CRA, Frogley MD, Cinque G, Wright PA, Howe RF (2019) ACS Catal 9:6564

7. Jost W (1960) Diffusion in Solids, Liquids and Gases. Academic Press, New York

8. Hoogschagen J (1955) Ind Eng Chem 47:906

9. Weisz PB (1973) Chem Tech 3:498

10. Karger J, Ruthven DM (1989) Zeolites 9:267

11. Jobic H, Theodorou DN (2007) Micro Meso Mater 102:21

12. O'Malley AJ, Catlow CRA (2017) Sorbate dynamics in zeolite catalysts. In: Fernandez-Alonso F, Price DL (eds) Experimental Methods in the Physical Sciences; Neutron Scattering - Applications in Biology, Chemistry, and Materials Science. Academic Press, Boca Raton, pp 349-401

13. O'Malley AJ, Parker SF, Catlow CRA (2017) Chem Commun 53:12164

14. Jobic H, Renouprez A, Bee M, Poinsignon C (1986) J Phys Chem 90:1059

15. Mitra S, Kamble VS, Tripathi AK, Gupta NM, Mukhopadhayay R (2004) Pramana J Phys 63:443

16. O'Malley AJ, Parker SF, Chutia A, Farrow MR, Silverwood IP, Sakai VG, Catlow CRA (2016) Chem Commun 52:2897

17. Matam SK, Omalley AJ, Catlow CRA, Suwardiyanto CP, Hawkins AP, Zachariou A, Lennon D, Silverwood IP, Parker SF, Howe RF (2018) Catal Sci Technol 8:3304

18. Matam SK, Nastae SAF, Logsdail AJ, Catlow CRA (2020) Chem Sci 11:6805
19. Arnold O, Bilheux JC, Borreguero JM, Buts A, Campbell SI, Chapon L, Doucet M, Draper N, Leal RF, Gigg MA, Lynch VE, Markvardsen A, Mikkelson DJ, Mikkelson RL, Miller R, Palmen K, Parker P, Passos G, Perring TG, Peterson PF, Ren S, Reuter MA, Savici AT, Taylor JW, Taylor RJ, Tolchenov R, Zhou W, Zikovsky J (2014) Instrum Methods Phys Res Sect A 764:156

20. Azuah RT, Kneller LR, Qiu Y, Tregenna-Piggott PLW, Brown CM, Copley JRD, Dimeo RM (2009) J Res Natl Inst Stand Technol 114(6):341

21. Omojola T, Silverwood IP, O’Malley AJ (2020) Catal Sci Technol 10:4305

22. Matam SK, Howe RF, Thetford A, Catlow CRA (2018) Chem Commun 54:12875

23. Sears VF (1966) Can J Phys 44(6):1279

24. Volino F, Dianoux AJ (1980) Mol Phys 41(2):271

25. Chudley CT, Elliott RJ (1961) Proc Phys Soc Lond 77(2):353

26. O'Malley AJ, Sarwar M, Armstrong J, Catlow CRA, Silverwood IP, York APE, Hitchcock I (2018) Phys Chem Chem Phys 20(17):11976

Publisher's Note Springer Nature remains neutral with regard to jurisdictional claims in published maps and institutional affiliations. 